\section{High-dose clopidogrel, prasugrel or ticagrelor: trying to unravel a skein into a ball}

\author{
Alessandro Aprile, Raffaella Marzullo, \\ Giuseppe Biondi-Zoccai, \\ Maria Grazia Modena, \\ Division of Cardiology, University of \\ Modena and Reggio Emilia, Modena, Italy
}

\begin{abstract}
Antiplatelet therapy is a mainstay in the management of coronary artery disease. Indeed, optimal and rapid inhibition of platelet function is a key therapeutic goal in patients with acute coronary syndromes and those undergoing percutaneous coronary intervention. Currently, dual antiplatelet treatment with aspirin and clopidogrel is the gold standard care in patients with acute coronary syndromes or receiving coronary stents without prohibitive bleeding risk. However, recent data show that the efficacy of clopidogrel is hampered by its slow and variable platelet inhibition, with ensuing increased risk of ischemic events, including death, myocardial infarction and stent thrombosis. Novel agents such as prasugrel and ticagrelor have been developed to clopidogrel limits and thus improve cardiovascular outcomes. This article presents a comprehensive overview of the benefits and limitations of current and shortly available antiplatelet agents, providing detailed arguments in favor and against prasugrel and ticagrelor.
\end{abstract}

\section{Introduction}

\section{Dual antiplatelet theraphy in patients with acute coronary artery disease}

Acute coronary syndromes (ACS) are the leading cause of mortality and hospital admission worldwide. In the last years, the great improvement of ACS treatment has been supported on one hand by the development of interventional devices and on the other hand by the major advances in antiplatelet therapy, including increased adherence. ${ }^{1-5}$

The main goal of optimal antiplatelet therapy in the setting of ACS is to minimize early and long term thrombotic adverse events, especially fatal or non-fatal myocardial infarction and stent thrombosis, as well as to reduce bleeding complications. ${ }^{6}$ Although aspirin still remains the cornerstone of antiplatelet thera- py in patient undergoing coronary revascularization and then for lifelong care, ${ }^{4,7-8}$ dual antiplatelet therapy with aspirin and a thienopyridine showed better clinical outcomes compared to aspirin alone in patients with ACS or aspirin plus warfarin in patients with ACS or receiving a coronary stent. ${ }^{9-12}$

The better safety and efficacy profile, including clinical outcomes after percutaneous coronary intervention (PCI), of clopidogrel (Plavix, Bristol Myers Squibb-Sanofi Aventis), a second generation thienopyridine, lead the large application in clinical practice of this drug over ticlopidine (Table 1). ${ }^{11-17}$ The efficacy of clopidogrel added to aspirin in patients with ACS was indeed largely established in the Clopidogrel in Unstable Angina to Prevent Recurrent Events (CURE) trial. ${ }^{11-12,18}$ This study randomized 12,562 patients to receive clopidogrel (loading dose of $300 \mathrm{mg}$ and maintaining dose of $75 \mathrm{mg}$ daily) or placebo in addition to aspirin. Clopidogrel plus aspirin lowered a composite of death, myocardial infarction, and stroke from $4.8 \%$ to $3.9 \%(\mathrm{P}=0.007)$ at 30 days and this benefit was durable through 12 months follow-up yielding a $20 \%$ relative reduction in risk (11.4\% to $9.3 \%$; $\mathrm{P}<0.001)$ regardless of aspirin dose. However, there was an increase in major bleeding events (3.7\% vs $2.7 \% ; \mathrm{P}=0.001$ ) with dual antiplatelet therapy. Despite the intense antiplatelet effect provided by aspirin plus clopidogrel, as much as $5.2 \%$ of such patients had a myocardial infarction, and $5.1 \%$ had died from cardiovascular causes at 1-year follow-up, suggesting that further improvements in ACS management could be made.

In the prospectively designed PCI-CURE substudy a strategy of clopidogrel pretreatment followed by long-term therapy was associated with a lower rate of cardiovascular death, myocardial infarction, or any revascularization $(\mathrm{P}=0.03)$, and of cardiovascular death or myocardial infarction $(\mathrm{P}=0.047)$ compared to placebo. ${ }^{12}$ Overall (including events before and after PCI), there was a $31 \%$ reduction in the risk of cardiovascular death or myocardial infarction $(\mathrm{P}=0.002)$. There was also less use of glycoprotein IIb/IIla inhibitors in the clopidogrel group $(\mathrm{P}=0.001)$. Intriguingly, at followup there was no significant difference in major bleeding between the groups $(\mathrm{P}=0.64){ }^{12}$

\section{Drawbacks of standard dose clopi- dogrel}

The persistence of enhanced platelet reactivity, despite a 300 to $600 \mathrm{mg}$ loading dose or 75 to $150 \mathrm{mg}$ maintenance dose of clopidogrel, is a clinically relevant entity and is due to a complex interplay between environmental and genetic factors. ${ }^{19}$ It is estimated that $30 \%$ of European, $40 \%$ of African, and more than 50\% of Asian patients exhibit a diminished
Correspondence: Giuseppe Biondi-Zoccai, Division of Cardiology, University of Modena and Reggio Emilia, via Del Pozzo 71, 41124 Modena Italy.

Tel: +39.059.422-57.83 - Fax: +39.059.422.37.14. E-mail: gbiondizoccai@gmail.com

Key words: acute coronary syndrome, coronary artery disease, clopidogrel, prasugrel, stent, ticagrelor.

Conflicts of interest: Dr. Biondi-Zoccai has lectured for AstraZeneca, Bristol Myers Squibb, and Sanofi Aventis.

Received for publication: 31 July 2011.

Revision received: 15 September 2011.

Accepted for publication: 27 September 2011.

This work is licensed under a Creative Commons Attribution NonCommercial 3.0 License (CC BYNC 3.0).

(C) Copyright A. Aprile et al., 2011

Licensee PAGEPress, Italy

Drugs and Therapy Studies 2011; 1:e13

doi:10.4081/dts.2011.e13

response to clopidogrel.

In a genetic substudy of the randomized Trial to Assess Improvement in Therapeutic Outcomes by Optimizing Platelet Inhibition with Prasugrel-Thrombolysis in Myocardial Infarction (TRITON-TIMI 38), the cytochrome CYP2C19 loss-of-function allele was significantly associated with risk of the primary endpoint of cardiovascular death, myocardial infarction, or stroke $(\mathrm{P}=0.0064) .{ }^{20}$ This result was confirmed by a meta analysis from 9 studies evaluating CYP2C19 genotype in patients treated with clopidogrel. Specifically, among 9685 subjects $(91.3 \%$ undergoing PCI and $54.5 \%$ with ACS), the composite end point of cardiovascular death, myocardial infarction, or stroke was significantly increased in both heterozygote and homozygote for reduced-function alleles (hazard ratio $=1.55[95 \%$ confidence interval 1.11-2.17], $\mathrm{P}=0.01$, and hazard ratio=1.76 [1.24-2.50], $\mathrm{P}=0.002$, respectively). Similarly, there was an increased risk of stent thrombosis in both groups with the hazard alleles. $^{21}$

Genetic variations affecting the cytochrome activity have been also correlated to pharmacologic interaction between clopidogrel and others drugs that fill the same enzymatic pathway. Particularly, several trials investigated the outcomes of patients concomitantly treated with clopidogrel and omeprazole, but results are equivocal: Ho and colleagues ${ }^{22}$ demonstrated that concomitant use of clopidogrel and PPI after hospital discharge for ACS was associated with an increased risk of adverse outcomes than use of clopidogrel alone; on the other 
side, in the COGENT trial ${ }^{23}$ there was no apparent cardiovascular interaction between clopidogrel and omeprazole, and clinical results did not rule out a clinically meaningful difference in cardiovascular events due to use of a PPI.

To identify the poor response to thienopyridine, several methods was developed in the clinical setting. Actually, Verify Now and Vasodilator Stimulated Phosphoprotein (VASP) are the most used test. Verify Now is a turbidimetric test which measures agonistinduced aggregation as an increase in light transmittance, and grants high clinical sensitivity and specificity. The cut-off between poor responders and responders in clinical trials ranges from 235 to $240 .{ }^{24}$ VASP is a flow cytometric assay which calculated the platelet reactivity index (PRI) from the median fluorescence intensity (MFI) of samples incubated with PGE1 or PGE1 and ADP. Non-response to clopidogrel was defined as PRI VASP > 50\%25 Although both Verify Now and VASP has been associated with clinical prognosis after PCI, ${ }^{24-28}$ recent study by Cuisset $e t$ al. demonstrated a poor agreement between different platelet assays and suggested that identification of clopidogrel non responders is test-dependent. ${ }^{29}$ Recently, modified release clopidogrel formulation is developed using its pharmaceutically acceptable salts. In animal model, the new clopidogrel napadisilate salt shows better stability and bioequivalence to the standard formulation suggesting a promising candidate for clinical setting. ${ }^{30}$

\section{Risk-benefit balance of high-dose clopidogrel}

Dual antiplatelet therapy by $600 \mathrm{mg}$ loading dose of clopidogrel provides faster and greater platelet inhibition in patients with ACS, which could translate into reduced adverse cardiac events. ${ }^{31-33}$ A meta-analysis from 10 studies by Lotrionte et al demonstrated that a high loading dose proved significantly superior to a standard loading dose in preventing cardiac death or nonfatal myocardial infarction $(\mathrm{P}=0.02)$, without any statistically significant increase in major or minor bleedings. ${ }^{2}$ Sensitivity analysis restricted to randomized trials confirmed such superiority of a high loading dose regimen $(\mathrm{P}=0.003)$. Accordingly, meta-regression disclosed a significant interaction between event rate and the benefits of high loading doses $(\mathrm{P}=0.005)$, suggesting that the greater the underlying risk, the greater the favorable impact of a high loading dose. ${ }^{2}$

These findings are in contrast with the largest randomized study on the topics, the Clopidogrel and Aspirin Optimal Dose Usage to Reduce Recurrent Events-Seventh Organization to Assess Strategies in Ischemic Syndromes (CURRENT OASIS 7) trial, in which 25,086 patients with ACS were random- ized to $600 \mathrm{mg}$ clopidogrel loading dose, followed by $150 \mathrm{mg}$ daily for a week and then 75 daily versus a $300 \mathrm{mg}$ loading dose, followed by $75 \mathrm{mg}$ daily maintenance therapy (Table 1). ${ }^{34}$ The primary end-point of cardiovascular death, myocardial infarction, or stroke at 30 days, was not significantly different in the two group $s$ (4.2\% in patients in the high dose group versus $4.4 \%$ in patients in the standard dose group; hazard ratio=0.95 [0.84-1.07]). However, among patients managed with PCI within 24 hours (approximately two thirds of the study patients), high dose clopidogrel yielded a statistically significant $15 \%$ reduction in the composite of cardiovascular, death, myocardial infarction, or stroke (3.9\% vs $4.5 \%$; hazard ratio $=0.85[0.74-0.99])$ that was driven mainly by significantly lower rates of myocardial infarction in the high dose clopidogrel group (2.0\% vs $2.6 \%$, HR $0.78,95 \%$ CI: 0.64 $0.95)$. There was also a significant $42 \%$ reduction in the risk of the key secondary endpoint of definite stent thrombosis in the high dose clopidogrel group $(0.7 \%$ vs $1.2 \%$; hazard ratio $=0.58[0.42-0.79])$. However, reduction in the rates of ischemic endpoints was offset by higher rates of major bleeding with the higher clopidogrel dose both in the entire study population $(2.5 \%$ vs $2.0 \%$; hazard ratio=1.25 [1.05$1.47])$ and in the PCI population (1.6\% vs $1.1 \%$; hazard ratio=1.44 [1.1-1.86]). ${ }^{34}$

Recently, the GRAVITAS trial investigated in

Table 1. Pharmacologic characteristics of novel oral antiplatelet agents.

\begin{tabular}{|c|c|c|c|c|c|c|c|c|}
\hline Drug & Category & Chemistry & Type & Administration & $\begin{array}{c}\text { CYP } \\
\text { metabolism }\end{array}$ & $\begin{array}{c}\text { Antiplatelet } \\
\text { effect }\end{array}$ & $\begin{array}{l}\text { Onset } \\
\text { of action }\end{array}$ & Dose \\
\hline TICLOPIDINE & $\begin{array}{l}1^{\text {st }} \text { generation } \\
\text { thienopyridine }\end{array}$ & & Prodrug & Oral & $\begin{array}{c}\text { Yes } \\
\text { (multiple } \\
\text { step process) }\end{array}$ & $\begin{array}{l}\text { Irreversibly ADP } \\
\text { P2Y12 receptor } \\
\text { antagonist }\end{array}$ & 5-7 days & $\begin{array}{l}\text { Loading dose: } \\
250 \mathrm{mg} \text { /day }\end{array}$ \\
\hline CLOPIDOGREL & $\begin{array}{l}2^{\text {nd }} \text { generation } \\
\text { thienopyridine }\end{array}$ & & Prodrug & Oral & $\begin{array}{c}\text { Yes } \\
\text { (multiple } \\
\text { step process) }\end{array}$ & $\begin{array}{l}\text { Irreversibly ADP } \\
\text { P2Y12 receptor } \\
\text { antagonist }\end{array}$ & $\begin{array}{l}\text { 2-9h } \\
\text { (Dose-dependent } \\
\text { inhibition of } \\
\text { latelet aggregation) }\end{array}$ & $\begin{array}{l}\text { Loading dose: } \\
\text { 300-600 mg/day } \\
\text { Maintenance dose: } \\
75-150 \text { mg/day }\end{array}$ \\
\hline PRASUGREL & $\begin{array}{l}3^{\text {rd }} \text { generation } \\
\text { thienopyridine }\end{array}$ & & Prodrug & Oral & $\begin{array}{c}\text { Yes } \\
\text { (single } \\
\text { step process) }\end{array}$ & $\begin{array}{l}\text { Irreversibly ADP } \\
\text { P2Y12 receptor } \\
\text { antagonist }\end{array}$ & $1-4 \mathrm{~h}$ & $\begin{array}{l}\text { Loading dose: } \\
60 \mathrm{mg} / \text { day } \\
\text { Maintenance dose: } \\
10 \mathrm{mg} / \text { day }\end{array}$ \\
\hline ELINOGREL & $\begin{array}{l}3^{\text {rd }} \text { generation } \\
\text { thienopyridine }\end{array}$ & & Active drug & $\begin{array}{l}\text { Intravenous } \\
\text { and Oral }\end{array}$ & No & $\begin{array}{l}\text { Competitive reversible } \\
\text { ADP P2Y12 receptor } \\
\text { antagonists }\end{array}$ & $\begin{array}{l}\text { IV: } \\
\text { immediate; } \\
\text { Oral: } 4 \mathrm{~h}\end{array}$ & $\begin{array}{l}\text { Loading dose: } \\
80 \mathrm{mg} \\
\text { (intravenous bolus) } \\
\text { Maintenance dose: } \\
\text { 100- } 150 \mathrm{mg} / \mathrm{bid} \\
\text { (oral) }\end{array}$ \\
\hline CANGRELOR & $\begin{array}{l}\text { Analogue } \\
\text { of adenosine } \\
\text { triphosphate }\end{array}$ & & Active drug & Intravenous & No & $\begin{array}{c}\text { Reversible direct-acting } \\
\text { ADP P2Y12 } \\
\text { receptor } \\
\text { antagonists }\end{array}$ & $3-6 \mathrm{~min}$ & $\begin{array}{l}\text { Bolus of } 30 \mathrm{~g} / \mathrm{kg} \\
\text { then an } \\
\text { infusion } \\
\text { of } 4 \mathrm{~g} / \mathrm{kg} / \mathrm{min}\end{array}$ \\
\hline TICAGRELOR & $\begin{array}{c}\text { Cyclopentyl } \\
\text { Triazolopyrimidine }\end{array}$ & & Active drug & Oral & No & $\begin{array}{l}\text { Selective } \\
\text { reversible ADP } \\
\text { P2Y12 receptor } \\
\text { inhibitor }\end{array}$ & $\begin{array}{l}1-3 \mathrm{~h} \\
\mathrm{mg} / \text { day }\end{array}$ & $\begin{array}{l}\text { Loading dose: } 180 \\
\text { Maintenance } \\
\text { dose: } \\
90 \text { mg bid }\end{array}$ \\
\hline
\end{tabular}


2214 patients the impact of high dose (150 $\mathrm{mg}$ ) versus standard dose (75 mg) clopidogrel in the 6 months following PCI. Investigators concluded that the use of high-dose clopidogrel compared with standard-dose clopidogrel did not reduce the incidence of death from cardiovascular causes, nonfatal myocardial infarction, or stent thrombosis. ${ }^{35}$

The impact of further increasing the loading dose of clopidogrel to $900 \mathrm{mg}$ has been evaluated recently but with inconclusive results. ${ }^{36}$

\section{Risk-benefit balance of prsugrel}

Prasugrel is a third generation thienopyridine that exerts its antiplatelet effect binding irreversibly to the P2Y12 ADP receptor by an active metabolite (Table 1). ${ }^{37-39}$ Treatment with prasugrel results in faster and greater platelet inhibition than standard or high-dose of clopidogrel and a lower rate of non-responders. $^{40-43}$

The Joint Utilization Of Medications To Block Platelets 0ptimally (JUMB0)-TIMI 26 trial was the first dose-finding study (phase II) focusing on this molecule in patients undergoing elective or urgent PCI.(41) Specifically, subjects were randomized to low dose $(40 \mathrm{mg}$ loading dose followed by $7.5 \mathrm{mg}$ daily), intermediate dose (60 mg loading dose followed by $10 \mathrm{mg}$ daily), or high dose (60 mg loading dose followed by $15 \mathrm{mg}$ daily) of prasugrel or the standard dose of clopidogrel (300 mg loading dose followed by $75 \mathrm{mg}$ daily). Treatment with prasugrel showed equivalent bleeding risk to clopidogrel ( $1.7 \%$ vs $1.2 \%$; hazard ratio $=1.42$ [0.40-5.0]), although more minimal bleeding was reported in the high dose prasugrel group compared with other prasugrel regimens and the clopidogrel group. There was a numerically lower incidence of major adverse cardiac events in the overall prasugrel group (7.2\%) compared with the clopidogrel group (9.4\%; $\mathrm{P}=0.26$; hazard ratio=0.76 [0.46-1.24]), primarily driven by a reduction in myocardial infarction and urgent reintervention.

In the TRITON-TIMI 38 study, 13,608 moderate-to high-risk ACS patients undergoing PCI were randomized to prasugrel (60 mg loading dose, $10 \mathrm{mg}$ daily maintenance dose) or clopidogrel (300 mg loading dose, $75 \mathrm{mg}$ daily maintenance dose) (Table 2). ${ }^{44}$ At 15 months, prasugrel proved more effective in reducing the risk of cardiovascular death, myocardial infarction, and stroke in comparison to clopidogrel (9.9\% vs $12.1 \%, \mathrm{P}<0.001)$. The difference between the treatment groups with regard to the rate of the this end-point was largely related to a significant reduction in myocardial infarction in the prasugrel group $(7.4 \%$ vs $9.7 \%, \mathrm{P}<0.001)$. The TRITON-TIMI 38 investigators also found significant reductions in the prasugrel group in the rates of urgent targetvessel revascularization $(3.7 \%$ vs $2.5 \%$,
$\mathrm{P}<0.001)$, and stent thrombosis $(2.4 \%$ vs $1.1 \%$, $\mathrm{P}<0.001)$. However, the more potent antiplatelet effect of prasugrel was associated with a significant increase of TIMI major bleeding $(2.5 \%$ vs $1.7 \%, \mathrm{P}=0.03)$, with the excess risk mainly due to coronary artery bypass grafting (CABG)-related major bleeding ( $0.4 \%$ vs $0.1 \%, \mathrm{P}=0.001)$. The balance of safety and efficacy favored clopidogrel over prasugrel especially in the elderly patients and in those weighing $<60 \mathrm{~kg}$ or with previous ischemic attack. $^{44}$

A much greater benefit of prasugrel therapy was showed in the subgroup analysis of STEMI patients in whom this drug reduced by $21 \%$ the combined end-point of cardiovascular death, myocardial infarction, or urgent target vessel revascularization compared with clopidogrel without increasing the rate of major bleeding complication. ${ }^{45}$ Similarly beneficial results were found among diabetics enrolled in the TRITON-TIMI 38 trial, as platelet inhibition with prasugrel resulted in a greater benefit in reducing ischemic events and improving outcomes in those with diabetes mellitus, concomitantly with no increase in bleeding risk. ${ }^{46}$

A post-hoc analysis was also performed in 12,844 patients undergoing PCI and stenting. The clinical benefit of prasugrel was similar with all stent types. Indeed, stent thrombosis was markedly and significantly reduced by prasugrel compared with clopidogrel in the overall cohort $(2.0 \%$ vs $0.8 \%, \mathrm{P}<0.0001)$, as well as in the stent subset. The greatest absolute benefits were seen in patients at higher risk for stent thrombosis, such as those with longer stents, bifurcation lesions, impaired kidney function, and diabetes. Similar benefits of prasugrel were also seen in patients who received the study drug before PCI ( $0.8 \%$ vs $2.2 \%$, hazard ratio=0.37, $\mathrm{P}=0.002$ ) or after coronary angioplasty was started (1.2\% vs $2.4 \%$, hazard ratio=0.51, $\mathrm{P}<0.0001, \mathrm{P}$ for interaction $=0.39) \cdot{ }^{47}$

Nonetheless, in a major recent twist, Bonello et al have challenged the uniformity of effect of prasugrel, in as much as been demonstrated for clopidogrel and aspirin. ${ }^{48-49}$ Specifically, they showed that among 301 patients with ACS treated with prasugrel, $25 \%$ had high on-treatment platelet reactivity. Moreover, patients with high on-treatment platelet reactivity had a significantly increased risk of major adverse cardiac events, but not an increased risk of bleeding.

Randomized trials demonstrated that the clinical benefits of plasugrel are limited in a population of age $>75$ years, previous TIA and/or stroke and a body weight less than 60 $\mathrm{kg}$. In this subset of patients, FDA contraindicates the use of plasugrel.

\section{Risk-benefit balance of ticagrelor}

Ticagrelor is the first reversible oral P2Y12 ADP receptor antagonist. Clinical pharmacology studies suggested an early and greater inhibition of platelet aggregation (2 hours to peak platelet inhibition) without a proportional increase in bleeding risk in comparison to clopidogrel (Table 1). ${ }^{50-51}$ The rapid reversal effect after discontinuation of the drug (within 12 hours) in fact minimizes the bleeding complications even in patients requiring surgical interventions. In the Dose conflrmation Study assessing anti-Platelet Effects of AZD6140 vs. clopidogRel in non-ST segment Elevation myocardial infarction (DISPERSE 2) trial, treatment with ticagrelor was associated with a numerically lower incidence of major bleeding among patients undergoing CABG 1-5 days after the drug stopping with a similar profile of safety and efficacy to clopidogrel.$^{52}$

The efficacy and safety of ticagrelor in the setting of ACS have been further evaluated in the phase III Platelet Inhibition and Patient Outcomes (PLATO) trial (Table 2). ${ }^{53}$ This study randomized approximately 18,000 patients, including those with ST-elevation as well as non-ST-elevation myocardial infarction, to 180 mg loading dose, $90 \mathrm{mg}$ twice daily thereafter of ticagrelor versus 300-600 mg loading dose, 75 mg daily thereafter of clopidogrel. All patients received aspirin (75-100 mg daily). During the 12-month follow-up period, the risk of death from vascular causes, myocardial infarction, or stroke was significantly reduced by ticagrelor (9.8\% vs $11.7 \%, \mathrm{P}<0.001$ ), an effect stemming from consistent reductions in the risk of death from all causes $(4.5 \%$ vs $5.9 \%, \mathrm{P}<0.001)$, death from vascular causes $(4.0 \%$ vs $5.1 \%, \mathrm{P}=0.001)$, and myocardial infarction $(5.8 \%$ vs $6.9 \%, \mathrm{P}=0.005)$, including stent thrombosis ( $1.3 \%$ vs $1.9 \%, \mathrm{P}=0.009)$. Stroke occurred with similar frequency in the ticagrelor and clopidogrel groups ( $1.5 \%$ vs $1.3 \%, \mathrm{P}=0.2)$, similarly to CABG-related major bleeding (4.8\% vs $5.2 \%$, $\mathrm{P}=0.3)$ and all TIMI major bleedings (7.1\% vs $6.9 \%, \mathrm{P}=0.7)$. However, non-CABG related bleeding still occurred more frequently in the ticagrelor group ( $2.8 \%$ vs $2.2 \%, \mathrm{P}=0.030)$ with a unfavorable trend especially for the intracranial bleeding $(0.3 \%$ vs $0.2 \%, \mathrm{P}=0.06)$. Ticagrelor patients had also higher incidences of dyspnea $(13.8 \%$ vs $7.8 \%, \mathrm{P}=0.001)$ and ventricular pauses (5.8\% vs $3.6 \%, \mathrm{P}=0.01)$ compared to clopidogrel..$^{53}$

A subgroup analysis of the PLATO trial ${ }^{54}$ showed a significant interaction between treatment and region $(\mathrm{P}=0.045)$, with less effect of ticagrelor in North America than in the rest of the world, probably due to higher (>300 mg) daily aspirin maintenance dose than in other regions. Authors observed that the lowest risk of cardiovascular death, myocardial infarction, or stroke with ticagrelor 


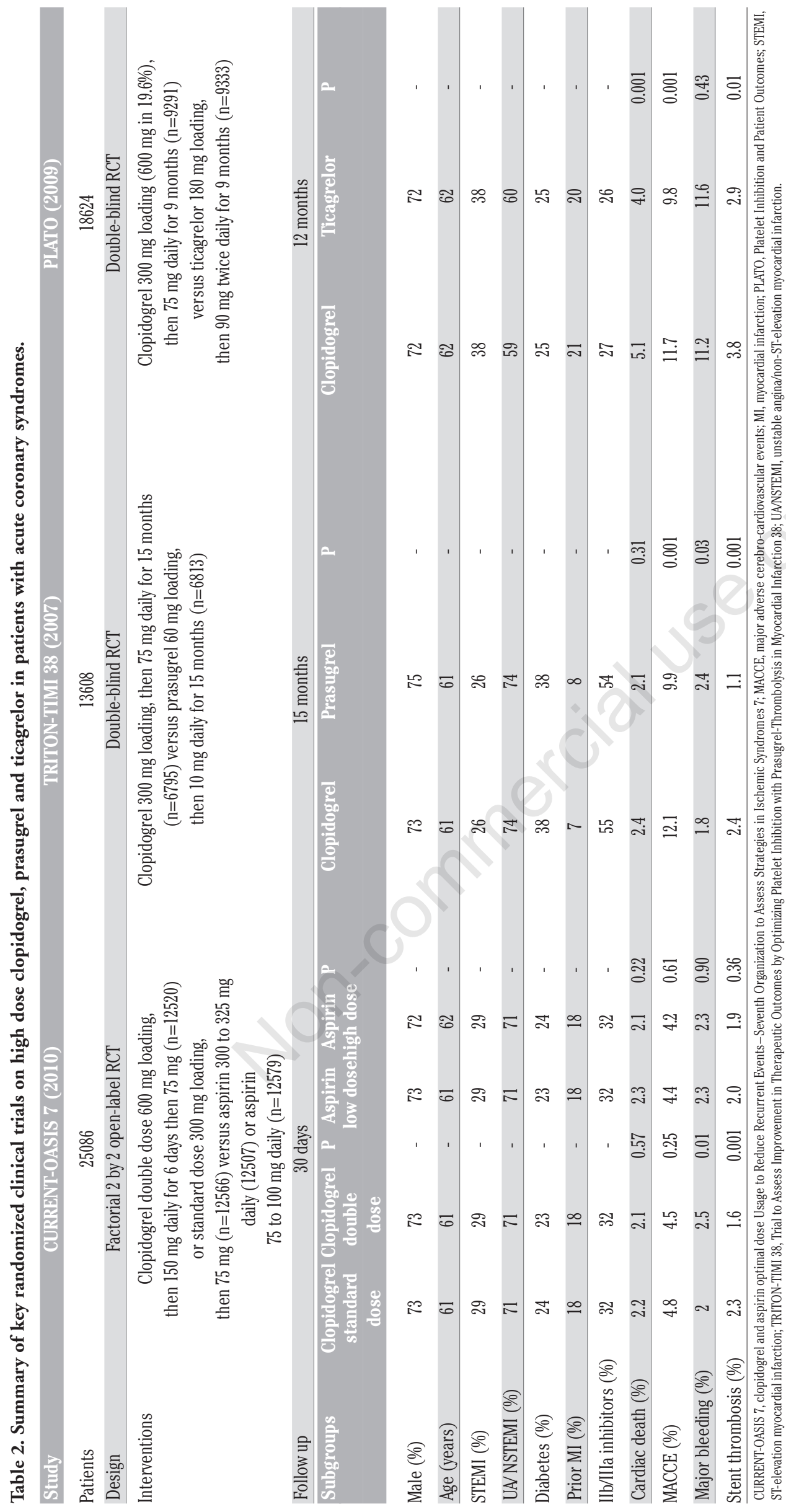


compared with clopidogrel is associated with a low maintenance dose of aspirin.

The antiplatelet effect of ticagrelor in patients who are nonresponsive to Clopidogrel was also investigated in the Response to Ticagrelor in Clopidogrel Nonresponders and Responders and Effect of Switching Therapies (RESPOND) study. ${ }^{55}$ The non- responsiveness to clopidogrel was defined as a $<10 \%$ absolute change in $20 \mu \mathrm{mol} / \mathrm{L}$ ADP-induced platelet aggregation between the baseline value and at 6-8 $\mathrm{h}$ after the $300 \mathrm{mg}$ clopidogrel loading dose. In a two-way crossover design, nonresponders and responders were randomly assigned to receive clopidogrel (600 $\mathrm{mg}$ loading dose then $75 \mathrm{mg}$ daily) or ticagrelor (180 mg loading dose then $90 \mathrm{mg}$ twice daily) for 14 days. The authors demonstrated that: i) ticagrelor was associated with greater platelet inhibition compared with clopidogrel treatment in both clopidogrel responders and nonresponders; ii) the antiplatelet effect of ticagrelor was largely not influenced by clopidogrel response status, and ticagrelor consistently overcame clopidogrel nonresponsiveness; iii) during switching of therapies, ticagrelor produced a rapid enhancement in platelet inhibition in both clopidogrel responders and nonresponders, whereas changing to clopidogrel therapy was associated with a reduction in platelet inhibition; and iv) ticagrelor was extremely effective in reducing the prevalence of high platelet reactivity without increases the ischemic risk. ${ }^{55}$

\section{Other antipiastinic drugs}

Cangrelor is an intravenous nonthienopyri- dine adenosine triphosphate analogue that blocks the adenosine diphosphate receptor P2Y12 (Table 1). It was compared to high dose (600 mg) loading clopidogrel in two large, phase 3, randomized clinical trials, in which cangrelor was administered before $\mathrm{PCI}^{56}$ or after PCI ${ }^{57}$ In both trials the primary efficacy end point was a composite of death from any cause, myocardial infarction, or ischemia-driven revascularization at 48 hours. In the CHAMPION PCI trial ${ }^{56}$ were enrolled 8877 patients. In the CHAMPION PLATFORM trial ${ }^{57}$ were enrolled 5362 patients. Cangrelor, administered both before and after PCI, was not superior to clopidogrel in reducing the primary end point.

Elinogrel is a P2Y12 blocker available in both intravenous and oral formulations (Table 1). INNOVATE-PCI ${ }^{58}$ is a phase 2 trial. The preliminary results have been presented at the ESC 2010 symposium. In the INNOVATE-PCI 616 patients were assigned pre-PCI to clopidogrel 300 or $600 \mathrm{mg}$ followed by $75 \mathrm{mg} /$ day, or to elinogrel $80 \mathrm{mg}$ IV bolus followed by 50 , or 150 $\mathrm{mg}$ oral elinogrel twice daily. Safety and efficacy endpoints were similar in the elinogrel low and high dose and clopidogrel group. Further phase 3 studies are actually scheduled to evaluate the impact of elinogrel on ACS patients.

\section{Direct and indirect comparison}

The main studies with employing high dose clopidogrel, prasugrel and ticagrelor in patients with ACS are summarized in Table 1. Although recent data suggest a superior antithrombotic efficacy of both prasugrel and tica-

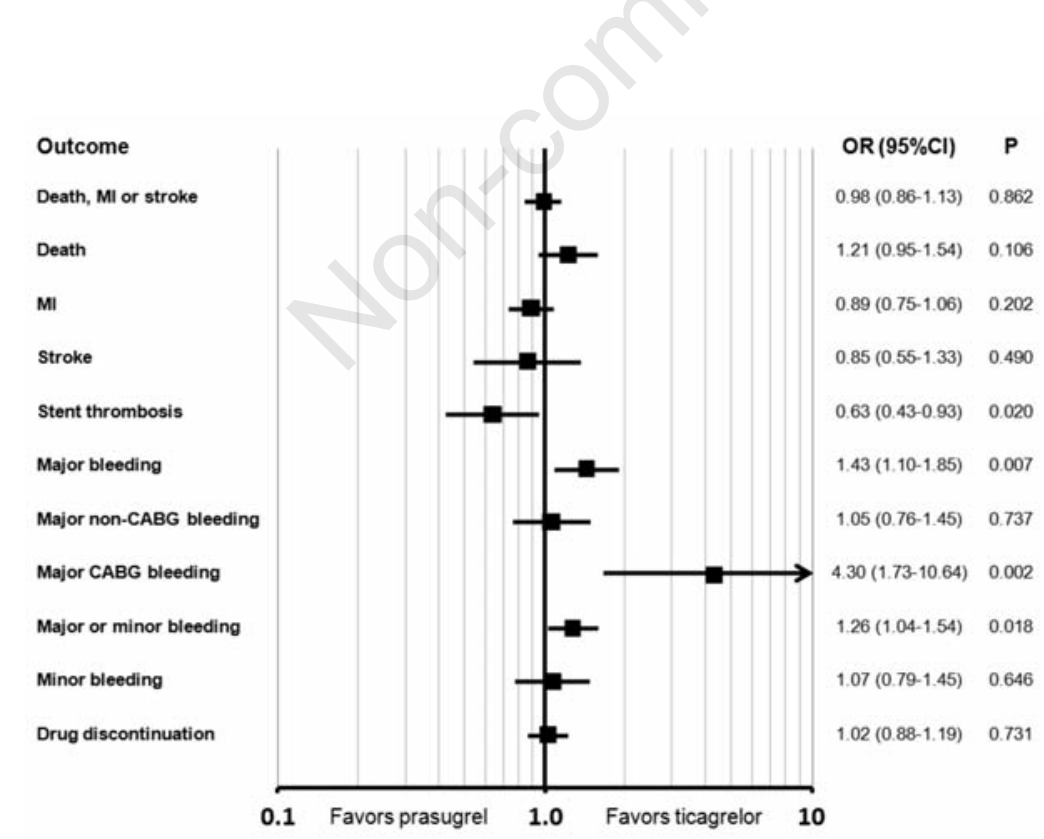

Figure 1. Adjusted indirect comparison meta-analysis of prasugrel vs. ticagrelor for the risk of key clinical events in patients with acute coronary syndromes. Odds ratios $(\mathrm{OR})<1.0$ favor prasugrel, whereas odds ratios $>1.0$ favor ticagrelor. CABG, coronary artery bypass grafting; CI,confidence interval; MI, myocardial infarction. Modified from Biondi-Zoccai et al. ${ }^{36}$ grelor in combination to aspirin instead of clopidogrel, a direct comparison between these drugs has not been performed yet, and is unlikely to be completed in the foreseeable future.

An indirect head-to-head comparison of prasugrel versus ticagrelor has nonetheless been recently performed by Biondi-Zoccai and colleagues, within the context of a adjusted metaanalysis. $^{59}$ The conclusion of this paper was that there were no significant difference in the risk of death (odds ratio=1.22 [0.96-1.55], $\mathrm{P}=0.106$ ), myocardial infarction (odds ratio=0.89 [0.75-1.06], $\mathrm{P}=0.202$ ), stroke (odds ratio=0.86 [0.55-1.33], $\mathrm{P}=0.490)$, major adverse cardiac events (odds ratio $=0.99$ [0.861.13], $\mathrm{P}=0.862$ ), major bleeding not related to CABG (odds ratio=1.06 [0.77-1.45], $\mathrm{P}=0.737$ ), minor bleeding (odds ratio=1.07 [0.79-1.45], $\mathrm{P}=0.646$ ), or drug discontinuation (odds ratio=1.03 [0.88-1.19], $\mathrm{P}=0.731$ ) (Figure 1).

However, this very same meta-analysis showed that prasugrel was associated with a significantly lower risk of definite or probable stent thrombosis in comparison to ticagrelor (odds ratio=0.64 [0.43-0.93], $\mathrm{P}=0.020$ ), albeit partially offset by an increased risk of major bleeding (odds ratio=1.43 [1.10-1.85], $\mathrm{P}=0.007$ ), mainly due to major bleeding related to CABG (odds ratio=4.30 [1.74-10.64], $\mathrm{P}=0.002$ ). These findings have already been externally validated in the context of a mixed treatment comparison. ${ }^{60}$

Conversely, Serebruany compared the findings of TRITON-TIMI 38 and PLATO trials, suggesting that ticagrelor, despite an unfavorable immediate safety profile, is clearly superior to prasugrel for chronic preventive use because of reductions inabsolute mortality, prevention of recurrent myocardial infarction, benefit on vascular outcomes which grows over time benefit, fewer bleeding fatalities, potentially fewer CABG- related bleedings, and lack of cancer risks. He concluded that ticagrelor will not substitute completely prasugrel, but in appropriate patients it will be a promising treatment. ${ }^{61}$

\section{Conclusions}

The choice of antiplatelet drug agent(s) should be based on the individual patient characteristics and the management strategy of ACS (Figure 2). Double loading dose and higher maintenance dose of clopidogrel may be considered for high risk patients. In those who experience adverse events despite ongoing clopidogrel therapy, alternative drugs may be envisioned. Prasugrel may indeed be preferred those at higher risk of thrombotic events, such as diabetics patients and/or those with diffuse coronary stenting. By its rapid onset of action, it may be preferred in patients 


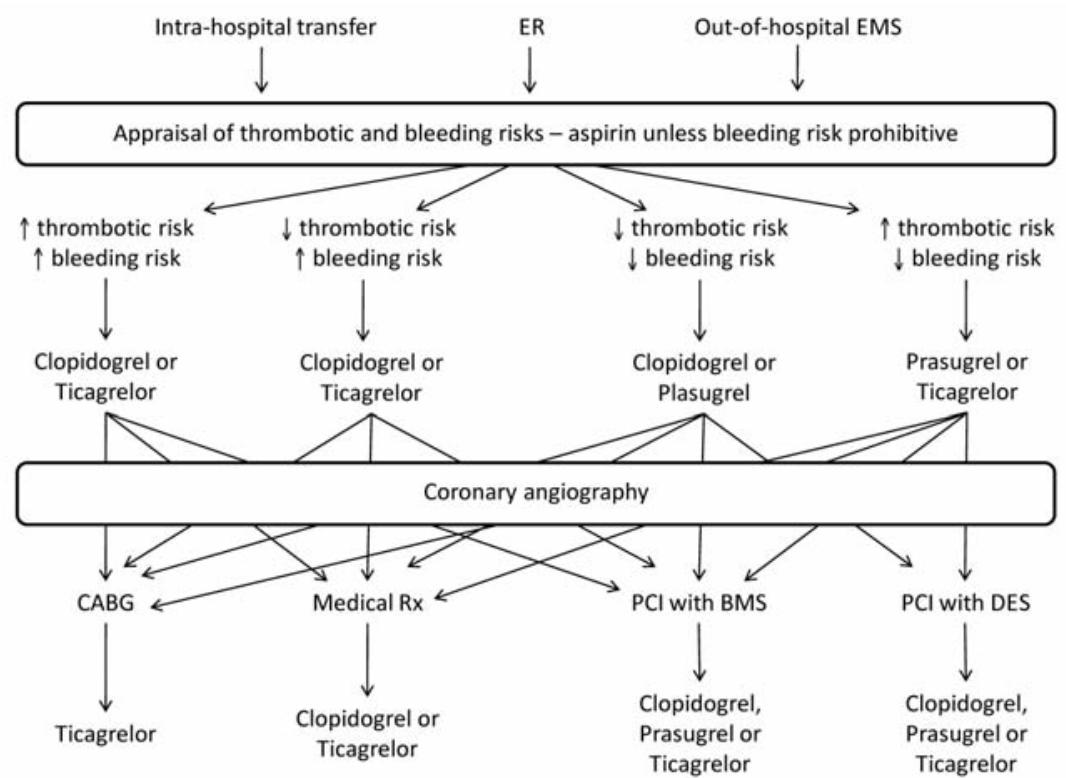

Figure 2. Simplified algorithm for oral antiplatelet therapy in patients with acute coronary syndromes. BMS, bare-metal stent; CABG, coronary artery bypass grafting; DES, drug-eluting stent; EMS, emergency medical services; ER, emergency room; PCI, percutaneous coronary intervention.

requiring urgent intervention and particularly in the ST-elevation myocardial infarction setting. This agent should be however avoided in those at higher risk of bleeding (underweight, old age, and prior cerebrovascular events), when clopidogrel or ticagrelor provide a more favorable risk-benefit balance.

Ticagrelor may be also preferred in patients in whom CABG is a viable option. Patients with lung disease, advanced renal failure, and rhythm disorders should however avoid ticagrelor. Finally, in selected situations of complex coronary interventions and need for rapid onset of ADP receptors inhibition but still concerns over long-term bleeding risk, a combination of short-term use of prasugrel $(60 \mathrm{mg} \mathrm{load}$ and $10 \mathrm{mg}$ maintenance for 3-7 days) followed by clopidogrel $75 \mathrm{mg}$ maintenance dose up to 1 year could be recommended.

All these approaches could also benefit by ad hoc measurement of platelet function and genotyping for key alleles, even if the cost-benefit implications of such personalized medicine approaches remain unclear. ${ }^{62}$

\section{References}

1. Biondi-Zoccai GG, Abbate A, Agostoni P et al. Long-term benefits of an early invasive management in acute coronary syndromes depend on intracoronary stenting and aggressive antiplatelet treatment: a metaregression. Am Heart J 2005; 149:50411.
2. Lotrionte M, Biondi-Zoccai GG, Agostoni P et al. Meta-analysis appraising high clopidogrel loading in patients undergoing percutaneous coronary intervention. Am J Cardiol 2007;100:1199-26.

3. Biondi-Zoccai G, Lotrionte M, Gaita F. Alternatives to clopidogrel for acute coronary syndromes: Prasugrel or ticagrelor? World J Cardiol 2010;2:131-4.

4. Biondi-Zoccai GG, Lotrionte M, Agostoni P et al. A systematic review and meta-analysis on the hazards of discontinuing or not adhering to aspirin among 50,279 patients at risk for coronary artery disease. Eur Heart J 2006;27:2667-74.

5. Landoni G, Augoustides JG, Guarracino F et al. Mortality reduction in cardiac anesthesia and intensive care: results of the first International Consensus Conference. Acta Anaesthesiol Scand 2011;55:259-66.

6. Antithrombotic Trialists' Collaboration. Collaborative meta-analysis of randomised trials of antiplatelet therapy for prevention of death, myocardial infarction, and stroke in high risk patients. BMJ 2002;324:71-86.

7. of discontinuing acetylsalicylic acid therapy in those at risk of coronary artery disease. Curr Opin Cardiol 2008;23:487-93.

8. Antithrombotic Trialists' (ATT) Aspirin in the primary and secondary prevention of vascular disease: collaborative meta-analysis of individual participant data from randomised trials. Lancet 2009;373:1849-60.

9. Schomig A, Neumann FJ, Kastrati A et al. A Collaboration, Baigent C, Blackwell L et al. randomized comparison of antiplatelet and anticoagulant therapy after the placement of coronary-artery stents. N Engl J Med 1996;334:1084-9.

10. Leon MB, Baim DS, Popma JJ, et al. A clinical trial comparing three antithromboticdrug regimens after coron coronary-artery stenting. N Engl J Med 1998;339:1665-71.

11. Yusuf S, Zhao F, Mehta SR et al. Effects of Clopidogrel in addition to aspirin in patients with acute coronary syndromes without ST-segment elevation. N Engl J Med 2001;345:494-502.

12. Mehta SR, Yusuf S, Peters RJ et al Clopidogrel in Unstable angina to prevent Recurrent Events trial (CURE) Investigators. Effects of pretreatment with Clopidogrel and aspirin followed by longterm therapy in patients undergoing percutaneous coronary intervention: the PCICURE study. Lancet 2001;358:527-33.

13. CAPRIE Steering Committee. A randomized, blinded trial of Clopidogrel versus aspirin in patients at risk of ischaemic events (CAPRIE). Lancet 1996;348:132939.

14. Bertrand ME, Rupprecht HJ, Urban P, et al. Double-blind study of the safety of Clopidogrel with and without a loading dose in combination with aspirin compared with ticlopidine in combination with aspirin after coronary stenting: the Clopidogrel Aspirin Stent International Cooperative Study (CLASSICS). Circulation 2000;102:624-9.

15. Bhatt DL, Bertrand ME, Berger PB et al. Meta-analysis of randomized and registry comparisons of ticlopidine with Clopidogrel after stenting. J Am Coll Cardiol 2002;39:9-14.

16. Bhatt DL, Fox KA, Hacke $W$ et al. Clopidogrel and aspirin versus aspirin alone for the prevention of atherothrombotic events. N Engl J Med 2006;354:170617.

17. Biondi-Zoccai GG, Lotrionte M, Agostoni P et al. Benefits of Clopidogrel in patients undergoing coronary stenting significantly depend on loading dose: evidence from a meta-regression. Am Heart J 2007;153: 587-93.

18. Peters RJ, Mehta SR, Fox KA et al. Effects of aspirin dose when used alone or in combination with Clopidogrel in patients with acute coronary syndromes: observations from the Clopidogrel in Unstable angina to prevent Recurrent Events (CURE) study. Circulation 2003;108:1682-7.

19. Hulot JS, Bura A, Villard E et al. Cytochrome P450 2C19 loss-of-function polymorphism is a major determinant of Clopidogrel responsiveness in healthy subjects, Blood 2006;108:2244-224.

20. Mega JL, Close SL, Wiviott SD et al. 
Cytochrome p-450 polymorphisms and response to Clopidogrel. $\mathrm{N}$ Engl $\mathrm{J}$ Med 2009;360:354-62.

21. Mega JL, Simon T, Collet JP et al. Reducedfunction CYP2C19 genotype and risk of adverse clinical outcomes among patients treated with Clopidogrel predominantly for PCI: a meta-analysis. JAMA 2010;304:182130.

22. Ho PM, Maddox TM, Wang L et al. Risk of adverse outcomes associated with concomitant use of clopidogrel and proton pump inhibitors following acute coronary syndrome. JAMA. 2009 Mar 4;301:937-44.

23. Bhatt DL, Cryer BL, Contant CF et al. Clopidogrel with or without omeprazole in coronary artery disease. N Engl J Med 2010;363:1909-17.

24. Price MJ, Endemann S, Gollapudi RR et al. Prognostic significance of post-clopidogrel platelet reactivity assessed by a point-ofcare assay on thrombotic events after drug-eluting stent implantation. Eur Heart J 2008, 29:992-1000.

25. Bonello L, Paganelli F, Arpin-Bornet M et al. Vasodilator-stimulated phosphoprotein phosphorylation analysis prior to percutaneous coronary intervention for exclusion of postprocedural major adverse cardiovascular events. J Thromb Haemost 2007;5: 1630-6.

26. Frere C, Cuisset T, Quilici J et al. ADPinduced platelet aggregation and platelet reactivity index VASP are good predictive markers for clinical outcomes in non-ST elevation acute coronary syndrome. Thromb Haemost 2007;98:838-43.

27. Cuisset T, Hamilos M, Sarma J et al. Relation of low response to clopidogrel assessed with point-of-care assay to periprocedural myonecrosis in patients undergoing elective coronary stenting for stable angina pectoris. Am J Cardiol 2008;101:1700-3.

28. Marcucci R, Gori AM, Paniccia R et al.Cardiovascular death and nonfatal myocardial infarction in acute coronary syndrome patients receiving coronary stenting are predicted by residual platelet reactivity to ADP detected by a point-ofcare assay: a 12-month follow-up. Circulation 2009;119:237-42.

29. Cuisset T, Frere C, Poyet R et al. Clopidogrel response: head-to-head comparison of different platelet assays to identify clopidogrel non responder patients after coronary stenting. Arch Cardiovasc Dis 2010;103:39-45.

30. Kim YI, Kim KS, Suh KH et al. New clopidogrel napadisilate salt and its solid dispersion with improved stability and bioequivalence to the commercial clopidogrel bisulphate salt in beagle dogs. Int J Pharm 2011;415:129-39.
31. Pache J, Kastrati A, Mehilli J et al. Clopidogrel therapy in patients undergoing coronary stenting: value of a high-loading-dose regimen. Catheter Cardiovasc Interv 2002;55:436-41.

32. Montalescot G, Sideris G, Meuleman C et al. A randomized comparison of high Clopidogrel loading doses in patients with non-ST-segment elevation acute coronary syndromes: the ALBION (Assessment of the Best Loading Dose of Clopidogrel to Blunt Platelet Activation, Inflammation and Ongoing Necrosis) trial. J Am Coll Cardiol 2006;48:931-8.

33. Biondi-Zoccai GG, Agostoni P, Testa L et al. Increased mortality after coronary stenting in patients treated with clopidogrel without loading dose. Evidence from a meta-analysis. Minerva Cardioangiol 2004;52:195-208.

34. Mehta SR, Tanguay JF, Eikelboom JW et al. Double-dose versus standard-dose Clopidogrel and high-dose versus low-dose aspirin in individuals undergoing percutaneous coronary intervention for acute coronary syndromes (CURRENT-OASIS 7): a randomised factorial trial. Lancet 2010;376:1233-43.

35. Price MJ, Berger PB, Teirstein PS et al. Standard- vs high-dose clopidogrel based on platelet function testing after percutaneous coronary intervention: the GRAVITAS randomized trial. JAMA 2011;305:1097-105.

36. von Beckerath N, Taubert D, PogatsaMurray G, et al. Absorption, metabolization, and antiplatelet effects of 300-, 600-, and 900- mg loading doses of Clopidogrel: results of the ISAR-CHOICE (Intracoronary Stenting and Antithrombotic Regimen: Choose Between 3 High Oral Doses for Immediate Clopidogrel Effect) trial. Circulation 2005;112:2946-50.

37. Testa L, Biondi Zoccai GG, Valgimigli M et al. Current concepts on antiplatelet therapy: focus on the novel thienopyridine and non-thienopyridine agents. Adv Hematol 2010;2010:595934.

38. Testa L, Bhindi R, Van Gaal WJ et al. What is the risk of intensifying platelet inhibition beyond clopidogrel? A systematic review and a critical appraisal of the role of prasugrel. QJM 2010;103:367-77.

39. Niitsu Y, Jakubowski JA, Sugidachi A, Asai F. Pharmacology of CS-747 (Prasugrel, LY640315), a novel, potent antiplatelet agent with in vivo P2Y12 receptor antagonist activity. Semin Thromb Hemost 2005;31:184-94.

40. Brandt JT, Payne CD, Wiviott SD et al. A comparison of prasugrel and clopidogrel loading doses on platelet function: magnitude of platelet inhibition is related to active metabolite formation. Am Heart $\mathrm{J}$ 2007;153:66 e9-16.

41. Wiviott SD, Antman EM, Winters KJ et al. Randomized comparison of Prasugrel (CS747. LY640315), a novel thienopyridine P2Y12 antagonist, with Clopidogrel in percutaneous coronary intervention: Results of the Joint Utilization Of Medications To Block Platelets Optimally (JUMBO)-TIMI 26 trial. Circulation 2005;111:3366-73.

42. Wiviott SD, Trenk D, Frelinger AL et al. Prasugrel compared with high loadingand maintenance- dose Clopidogrel in patients with planned percutaneous coronary intervention: the Prasugrel in Comparison to Clopidogrel for Inhibition of Platelet Activation and AggregationThrombolysis in Myocardial Infarction 44 trial. Circulation 2007;116:2923-32.

43. Jernberg T, Payne CD, Winters KJ et al. Prasugrel achieves greater inhibition of platelet aggregation and a lower rate of non-responders compared with Clopidogrel in aspirin-treated patients with stable coronary artery disease. Eur Heart J 2006;27:1166-73.

44. Wiviott SD, Braunwald E, McCabe CH et al. Prasugrel versus clopidogrel in patients with acute coronary syndromes. N Engl J Med 2007;357:2001-15.

45. Montalescot G, Wiviott SD, Braunwald E et al. Prasugrel compared with Clopidogrel in patients undergoing percutaneous coronary intervention for ST-elevation myocardial infarction (TRITON-TIMI 38): doubleblind, randomised controlled trial. Lancet 2008;371:1353-63.

46. Montalescot G, Wiviott SD, Braunwald E et al. Greater clinical benefit of more intensive oral antiplatelet therapy with Prasugrel in patients with diabetes mellitus in the Trial to Assess Improvement in Therapeutic Outcomes by Optimizing Platelet Inhibition with PrasugrelThrombolysis in Myocardial Infarction 38. Circulation 2008;118: 1626-36.

47. Wiviott SD, Braunwald E, McCabe CH et al. Intensive oral antiplatelet therapy for reduction of ischaemic events including stent thrombosis in patients with acute coronary syndromes treated with percutaneous coronary intervention and stenting in the TRITON-TIMI 38 trial: a subanalysis of a randomised trial. Lancet 2008; 371:1353-63.

48. Biondi-Zoccai G, Lotrionte M. Aspirin resistance in cardiovascular disease. BMJ 2008;336:166-7.

49. Bonello L, Pansieri M, Mancini J et al. High on-treatment platelet reactivity after prasugrel loading dose and cardiovascular events after percutaneous coronary intervention in acute coronary syndromes. J Am Coll Cardiol 2011;58:467-73. 
50. Husted S, Emanuelsson H, Heptinstall S, et al. Pharmacodynamics, pharmacokinetics, and safety of the oral reversible P2Y12 antagonist AZD6140 with aspirin in patients with atherosclerosis: a doubleblind comparison to Clopidogrel with aspirin. Eur Heart J 2006;27:1038-47.

51. Peters G, Robbie G. Single dose pharmacokinetics and pharmacodynamics of AZD6140 - an oral reversible ADP receptor antagonist. Haematologica 2004;89Suppl7:14-5.

52. Cannon CP, Husted S, Harrington RA et al. Safety, tolerability, and initial efficacy of AZD6140, the first reversible oraladenosine diphosphate receptor antagonist, compared with Clopidogrel, in patients with non-ST-segment elevation acute coronary syndrome: Primary results of the DISPERSE-2 trial. J Am Coll Cardiol 2007;50:1844-51.

53. Wallentin L, Becker RC, Budaj A et al. Ticagrelor vs. Clopidogrel in patients with acute coronary syndromes. N Engl J Med 2009;361:1045-57.
54. Mahaffey KW, Wojdyla DM, Carroll K et al. Ticagrelor Compared With Clopidogrel by Geographic Region in the Platelet Inhibition and Patient Outcomes (PLATO) Trial. Circulation 2011;124:544-54.

55. Gurbel PA, Bliden KP, Butler K et al. Response to Ticagrelor in Clopidogrel nonresponders and responders and effect of switching therapies: The RESPOND study. Circulation 2010;121:1188-99.

56. Harrington RA, Stone GW, McNulty S et al. Platelet inhibition with cangrelor in patients undergoing PCI. N Engl J Med 2009;361:2318-29.

57. Bhatt DL, Lincoff AM, Gibson CM et al. Intravenous platelet blockade with cangrelor during PCI. N Engl J Med 2009;361: 2330-41.

58. Leonardi S, Rao SV, Harrington RA et al. Rationale and design of the randomized, double-blind trial testing INtraveNous and Oral administration of elinogrel, a selective and reversible P2Y(12)-receptor inhibitor, versus clopidogrel to eVAluate Tolerability and Efficacy in nonurgent
Percutaneous Coronary Interventions patients (INNOVATE-PCI). Am Heart J 2010;160:65-72.

59. Biondi-Zoccai G, Lotrionte M, Agostoni P et al. Adjusted indirect comparison metaanalysis of prasugrel versus ticagrelor for patients with acute coronary syndromes. Int J Cardiol 2011;150:325-31.

60. Biondi-Zoccai G, D'Ascenzo F, Abbate A et al. Agreement between adjusted indirect comparison and simplified network metaanalyses on prasugrel and ticagrelor (Reply to Passaro et al. - Int J Cardiol 2011). Int J Cardiol 2011;151:228;9.

61. Serebruany VL. The TRITON versus PLATO trials: differences beyond platelet inhibition. Thromb Haemost 2010;103:259-61.

62. Campo G, Parrinello G, Ferraresi P et al. Prospective evaluation of on-clopidogrel platelet reactivity over time in patients treated with percutaneous coronary intervention relationship with gene polymorphisms and clinical outcome. J Am Coll Cardiol 2011;57:2474-83. 